\title{
Traumatic asphyxia: a rare syndrome in trauma patients
}

\author{
Cenker Eken • Ozlem Yigit
}

Received: 20 March 2009 / Accepted: 25 May 2009/Published online: 1 August 2009

(C) Springer-Verlag London Ltd 2009

A 6-year-old boy was admitted to the emergency department (ED) suffering from petechiae and purpura on his face caused by a farming accident. He got his T-shirt caught in a rotating shaft at the back of a tractor. The T-shirt wrapped around his thorax and compressed him. He did not lose his consciousness during the incident. His score on the Glasgow Coma Scale was 15 and his initial vital signs were stable upon arrival at the ED. On physical examination, diffuse petechiae and purpura were noted on the face and neck although there was not any sign of the direct trauma (Figs. 1 and 2). The patient denied suffering head trauma. Examination for abdominal and thoracic organ injury was negative.

Traumatic asphyxia is a rare condition presenting with cervicofacial cyanosis and edema, subconjunctival hemorrhage, and petechial hemorrhages of the face, neck, and upper chest that occurs due to a compressive force to the thoracoabdominal region [1]. Although the exact mechanism is controversial, it is probably due to thoracoabdominal compression causing increased intrathoracic pressure

C. Eken $(\bowtie) \cdot$ O. Yigit

Department of Emergency Medicine,

Akdeniz University Faculty of Medicine,

07059 Antalya, Turkey

e-mail: cenkereken@akdeniz.edu.tr

O. Yigit

e-mail: ozlemyigit@akdeniz.edu.tr

C. Eken $\cdot$ O. Yigit

Department of Emergency Medicine,

Akdeniz University School of Medicine,

07059 Antalya, Turkey just at the moment of the event. The fear response, which is characterized by taking and holding a deep breath and closure of the glottis, also contributes to this process $[1,2]$. This back pressure is transmitted ultimately to the head and neck veins and capillaries, with stasis and rupture producing characteristic petechial and subconjunctival hemorrhages [2]. The skin of the face, neck, and upper torso may appear blue-red to blue-black but it blanches over time. The discoloration and petechiae are often more prominent on the eyelids, nose, and lips [3]. In patients with traumatic asphyxia, injuries associated with other systems may also accompany the condition. Jongewaard et al. reported chest wall and intrathoracic injuries in 11 patients, loss of consciousness in 8 , prolonged confusion in 5 , seizures in 2, and visual disturbances in 2 of 14 patients with traumatic asphyxia [4]. Pulmonary contusion, hemothorax, pneumothorax, prolonged loss of consciousness,

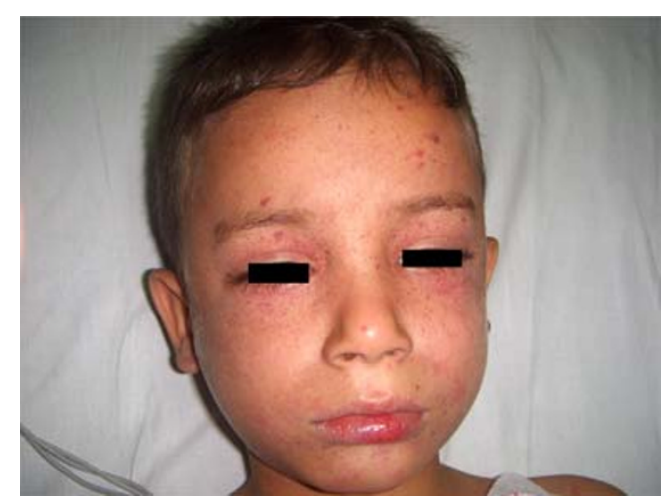

Fig. 1 Diffuse petechiae and purpura throughout face and eyelids and submucosal hemorrhages on the lower lip 


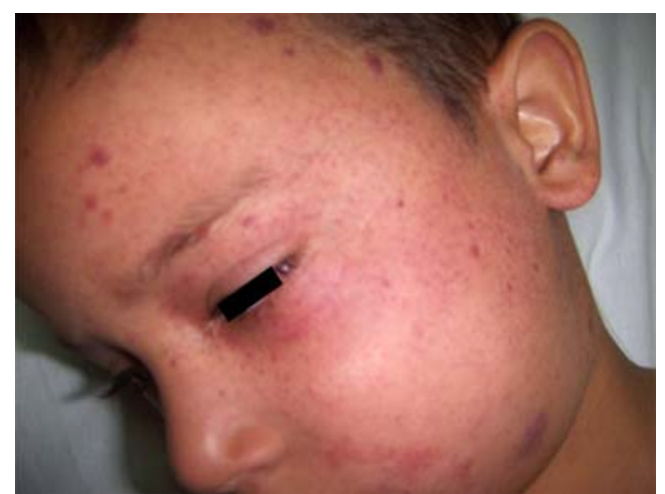

Fig. 2 Petechiae, purpura, and ecchymosis on the left side of the face

confusion and seizures, ophthalmic injuries such as exophthalmos, retinal hemorrhages and visual loss, and abdominal injuries such as liver and splenic lacerations and gastrointestinal hemorrhage have also been reported in patients with traumatic asphyxia $[1,5,6]$. Traumatic asphyxia has a good prognosis. Supportive treatment such as oxygenation and elevation of the head to $30^{\circ}$ is usually sufficient in the management of these patients. However, specific treatments may be needed for the associated injuries.

\section{References}

1. Richards CE, Wallis DN (2005) Asphyxiation: a review. Trauma 7:37-45

2. Williams JS, Minken SL, Adams JT (1968) Traumatic asphyxiareappraised. Ann Surg 167(3):384-392

3. Lee MC, Wong SS, Chu JJ et al (1991) Traumatic asphyxia. Ann Thorac Surg 51(1):86-88

4. Jongewaard WR, Cogbill TH, Landercasper J (1992) Neurologic consequences of traumatic asphyxia. J Trauma 32(1):28-31

5. Ghali GE, Ellis E 3rd (1989) Traumatic asphyxia: report of a case. J Oral Maxillofac Surg 47:867-870

6. Sklar DP, Baack B, McFeeley P, Osler T, Marder E, Demarest G (1988) Traumatic asphyxia in New Mexico: a five-year experience. Am J Emerg Med 6:219-223 